\title{
Risk Critical Point (RCP): A Quantifying Safety-Based Method Developed to Screen Construction Safety Risks
}

\author{
Mehdi Soltanmohammadi \\ Project Management and Construction Group, College of Fine Arts, University of Tehran, Tehran, Iran \\ Morteza Saberi \\ School of Information Science, Curtin University of Technology, Perth, Austrailia \\ Jin Hee Yoon* \\ School of Mathematics and Statistics, Sejong University, Seoul, Korea \\ Khatereh Soltanmohammadi \\ Project Management and Construction Group, Mehralborz University, Tehran, Iran \\ Peiman Pazhoheshfar \\ Young Researchers and Elite Club, Arak Branch, Islamic Azad University, Arak, Iran
}

(Received: February 17, 2014 / Revised: February 3, 2015; July 23, 2015 / Accepted: August 31, 2015)

\begin{abstract}
Risk assessment is an important phase of risk management. It is the stage in which risk is measured thoroughly to achieve effective management. Some factors such as probability and impact of risk have been used in the literature related to construction projects. Because in high-rise projects safety issues are paramount, this study has tried to develop a quantifying technique that takes into account three factors: probability, impact and Safety Performance Index (SPI) where the SPI is defined as the capability of an appropriate response to reduce or limit the effect of an event after its occurrence with regard to safety pertaining to a project. Regarding risk-related literatures which cover an uncertain subject, the proposed method developed in this research is based on a fuzzy logic approach. This approach entails a questionnaire in which the subjectivity and vagueness of responses is dealt with by using triangular fuzzy numbers instead of linguistic terms. This method returns a Risk Critical Point (RCP) on a zoning chart that places risks under categories: critical, critical-probability, critical-impact, and non-critical. The high-rise project in the execution phase has been taken as a case study to confirm the applicability of the proposed method. The monitoring results showed that the RCP method has the inherent ability to be extended to subsequent applications in the phases of risk response and control.
\end{abstract}

Keywords: Risk Assessment, Safety Performance Index (SPI), Fuzzy Logic, Risk Critical Point (RCP)

* Corresponding Author, E-mail: jin9135@sejong.ac.kr

\section{INTRODUCTION}

The assessment of risk level associated with on-site hazards is an essential component of the risk management process which estimates the magnitude of risk and ascertains whether or not the risk is tolerable (Fung et 
al., 2011). Risk response and controlling strategy decisions cannot be made in the subsequent phases unless the risk is identified and assessed through a perceivable process (Baker et al., 1999).

According to the existing literature (Table 1), there are various techniques for evaluating risk including event trees (Chapman, 2001), AHP analysis (Zayed et al., 2007), Correlation matrix (El-Sayegh, 2007), Monte Carlo Simulation (Stroeve et al., 2009), multi-attribute group decision making (MAGDM) (Mohammad et al., 2010), Fault Trees (Lin et al., 2011), entropy measurement (Xiao-mei and Xiao-jun, 2011), qualitative and quantitative risk evaluation model (Q2REM) (Fung et al., 2011), Fuzzy method (Roisenberg et al., 2009; Xu et al., 2010; Deng et al., 2011; KarimiAzari et al., 2011; Kucukali, 2011; Nieto-Morote and Ruz-Vila; 2011, Fouladgar et al., 2012), Occupational Risk Model (Aneziris et al., 2010; Aneziris et al., 2011; Pinto et al., 2011), Bayesian networks (Sousa and Einstein, 2012), artificial neural network model (Chenyun and Zichun, 2012) in addition to numerous traditional tools and methods such as check list, Delphi method, brain storm method, SWOT analysis method, sensitivity analysis, system analysis method, WBS method and experience judgment method, to name a few (Guofeng et al., 2011).

Among the literature concerning risk assessment, Kaming et al. (1997) recommended that severity of oc- currence can also be considered for each risk event in addition to two current indexes namely, probability of risk occurrence and risk impact in the whole project. In this method, the considered risks were assessed by using a correlation matrix technique, a mathematical method which shows the relationship between the risk events in a square matrix. Ivan et al. (2010) developed a similar method namely, the Risk Assessment Model (RAM), as the prototype of an efficient risk evaluation tool for promoting occupational injury prevention priorities for workers in different trades.

As can be seen, Table 1 summarizes instances of commonly applied approaches in addition to several others which deal with complexities encountered in the phase of risk assessment.

It is clear that all the attempts made in the field of risk management study, specifically in the assessment phase, will enhance the performance of a project throughout the stages of its life cycle. Despite the variety of methods presented for risk assessment, no study has attempted to show that which safety risk in comparison with the others can make an outstanding effect on project performance in terms of the criteria of safety, cost, time, and environmental sustainability. By using appropriate risk assessment method in the planning stage of the project life cycle and therefore the suitable risk measurements in the next project stages, management

Table 1. A number of methods introduced for risk assessment in the existent literature

\begin{tabular}{|c|c|c|c|}
\hline Method & Project type & Place & Reference \\
\hline Event Trees & Construction & - & Chapman, 2001 \\
\hline AHP Analysis & Highway & China & Zayed et al., 2007 \\
\hline Correlation Matrix & Construction & UAE & El-Sayegh, 2007 \\
\hline Monte Carlo Simulation & Air traffic control & Netherland & Stroeve et al., 2009 \\
\hline $\begin{array}{l}\text { Multi-Attribute Group Decision } \\
\text { Making (MAGDM) }\end{array}$ & Gas refinery plant & Iran & Mohammad et al., 2010 \\
\hline Fault Trees & Railway engineering construction & China & Wang Lin et al., 2011 \\
\hline Entropy Measurement & Construction & China & Xiao-mei and Xiao-jun, 2011 \\
\hline $\begin{array}{l}\text { Qualitative and Quantitative Risk } \\
\text { Evaluation Model (Q2REM) }\end{array}$ & Construction & Hong Kong & Fung et al., 2011 \\
\hline \multirow{8}{*}{ Fuzzy Method } & Construction & - & Guranli and Mungen, 2008 \\
\hline & Petroleum exploration & - & Mauro Roisenberg, 2009 \\
\hline & Public-Private partnership (PPP) & China & Yelin Xu et al., 2010 \\
\hline & - & - & Yong Deng, 2011 \\
\hline & Construction & Iran & Karimi Azari et al., 2011 \\
\hline & River-type hydropower plant & Turkey & Kucukali, 2011 \\
\hline & Construction & Spain & Nieto-Morote and Ruz-Vila, 2011 \\
\hline & Tunnel Construction & Iran & Fouladgar et al., 2012 \\
\hline \multirow{3}{*}{ Occupational Risk Model (ORCA) } & Tunnel Construction & Greece & Aneziris et al., 2010 \\
\hline & Construction & Greece & Aneziris et al., 2011 \\
\hline & Construction & - & Abel Pinto et al., 2011 \\
\hline Bayesian Networks & Tunnel Construction & Portugal & Sousa and Einstein, 2012 \\
\hline Artificial Neural Network Model & Expressway Construction & China & Chenyun and Zinchun, 2012 \\
\hline
\end{tabular}


can be more confident about meeting the project performance criteria. Currently, decision-makers do not have a project performance-based method whereby they can choose an appropriate risk response and subsequently modify it according to changes in project conditions. The most eminent study in this regard has been done by Fouladgar et al. (2012) in which the authors suggest a new framework for evaluating risk that adds a reaction criteria to the probability and impact factors of risk. Reaction to an event has been described as the capability of an appropriate response in order to reduce or limit the effect of an event after its occurrence or prevent the likelihood of casualties, damage, and loss. However, they provide no clear concept of assessed risk in order to identify the amount of safety expected in the later, execution phase of the project life cycle. Moreover, the major focus of each proposed model for risk assessment seems to be the achievement of tight cohesion of the other risk management steps. In this study, we attempt to strengthen the relationship between risk assessment and subsequent phases, namely risk response and control, in order to maximize project performance according to the aforementioned criteria.

As can be found in the recent studies in the field of construction, the construction industry is statistically one of the most hazardous industries in many countries (Gangolells et al., 2010; Caponecchia and Sheils, 2011; Carbonari et al., 2011; Aneziris et al., 2011). This essential matter has produced several significant research findings concerning safety issues in risk assessment. In this study, we consider a unique type of construction in Iran, namely, the Milad Tower. There are no other similar local cases, and the many hazards pertaining to this project have been problematic for the owner. Moreover, this case is accessible and suitable for the purposes of this study since we can improve the safety level of the project by implementing our proposed method.

In this paper, a safety-based approach is utilized to assess the identified risks. This approach is of significant value for high-rise construction projects because safety is one of the five objectives of all projects apart from cost, time, quality, and environmental sustainability, and plays a considerably critical role compared to the other objectives in the high-rise construction industry. In this study, this issue has led us to propose a quantifying safety-based method called Risk Critical Point (RCP) in which a zoning chart is utilized that places risks in four categories, namely: critical, critical-probability, critical-impact, and non-critical. In the following, we discuss how this can be used in the later stages of risk management. The graphical flowchart shown in Figure 1 illustrates the conceptual steps applied in the RCP method.

\section{RISK CRITICAL POINT (RCP) FRAMEWORK}

It is understood that the most effective way to im- prove safety performance is to prevent accidents from occurring in the first place. Thus, safety risk analysis is a necessary foundation upon which safety management can be built and risk assessment becomes a critical task which forms an integral part of safety management systems (Fung et al., 2010). An effective risk assessment can provide a proactive approach to help organizations prevent accidents from the outset, thereby preventing losses (Fung et al., 2011). In order to undertake safety risk analysis, and since the assessment and tracking of the all identified risk events are not practicable in complex projects, firstly it is essential to identify the safety risk events.

A large number of techniques exist for risk identification. These include: brainstorming and workshops, checklists and prompt lists, questionnaires and interviews, Delphi groups or nominal group technique (NGT), and various diagramming approaches such as cause-effect diagrams, systems dynamics, influence diagrams (Mohammad et al., 2010). Given that risk assessment is the main focus of this study, and because of the dearth of safety professionals in Iranian projects during their initiating and planning stages, this study adopts a categorizing system following the study by Fung et al. (2011). According to this study, the following factors should be taken into account for risk identification:

- Materials, equipment/plants used for the task/acti-vities.

- Authority for delegation, training and ability to cope in an emergency.

- Working conditions, like any hazards in the workplace, effect of weather conditions or lighting and hazards from adjacent processes or contractors.

- The working procedures, like examining any potential failures in working methods.

Using the above classifications which have led to the identification of 33 threats to project safety, and taking into account the information acquired from interviews with project experts, we present in Table 2 a comprehensive list of categories and sub-categories of risks in the conditional Iranian construction projects. These identified safety risks will be processed later using a step-by-step method.

Using the above classifications and possible accident causes have led to the determination of 33 threats to project safety which the applicability of each of them to our case as a risk has been reviewed and confirmed through expert interviews as well (Table 2).

After determining the safety risks, an assessment phase follows in which each risk is precisely measured in order to increase the efficiency of management. In this phase, the recognition of which risks is important that can help managers to determine:

(1) How much time will be allocated to select the best response to critical risks; and

(2) How much resource will be allocated to select the best response to critical risks? 
Table 2. Overall identified safety risks using the RCP method

\begin{tabular}{|c|c|c|}
\hline Risk Codes & Risk Category & Risk Sub-category \\
\hline $\mathrm{R}_{1}$ & \multirow{9}{*}{ Insufficient management control } & Improper or insufficient delegation \\
\hline $\mathrm{R}_{2}$ & & Inadequate monitoring of works \\
\hline $\mathrm{R}_{3}$ & & Inadequate safety training \\
\hline $\mathrm{R}_{4}$ & & Inadequate supervision/management \\
\hline $\mathrm{R}_{5}$ & & Inadequate specification \\
\hline $\mathrm{R}_{6}$ & & Poor accident reporting system \\
\hline $\mathrm{R}_{7}$ & & Poor planning for working sequences \\
\hline $\mathrm{R}_{8}$ & & Inadequate review of safety performance \\
\hline $\mathrm{R}_{9}$ & & Inadequate accident preventative measurement \\
\hline $\mathrm{R}_{10}$ & \multirow{8}{*}{ Unsafe practice } & Improper use of tools and equipment \\
\hline $\mathrm{R}_{11}$ & & Inadequate personal protective equipment \\
\hline $\mathrm{R}_{12}$ & & Improper operating/working speed \\
\hline $\mathrm{R}_{13}$ & & Improper handling site materials \\
\hline $\mathrm{R}_{14}$ & & Failure to give warning/secure \\
\hline $\mathrm{R}_{15}$ & & Lack of repair/maintenance \\
\hline $\mathrm{R}_{16}$ & & Lack of pre-use equipment inspection \\
\hline $\mathrm{R}_{17}$ & & Use of inherent hazardous method/procedure \\
\hline $\mathrm{R}_{18}$ & \multirow{7}{*}{ Unsafe practice substandard conditions } & Poor housekeeping \\
\hline $\mathrm{R}_{19}$ & & Improper illumination \\
\hline $\mathrm{R}_{20}$ & & Inadequate ventilation \\
\hline $\mathrm{R}_{21}$ & & Inadequate traffic control \\
\hline $\mathrm{R}_{22}$ & & Inadequate working space \\
\hline $\mathrm{R}_{23}$ & & Unguarded mechanical/physical hazards \\
\hline $\mathrm{R}_{24}$ & & Unlabeled or inadequately labeled materials \\
\hline $\mathrm{R}_{25}$ & \multirow{5}{*}{ Personal factors } & Inadequate instruction \\
\hline $\mathrm{R}_{26}$ & & Poor judgment \\
\hline $\mathrm{R}_{27}$ & & Poor coordinate/communication \\
\hline $\mathrm{R}_{28}$ & & Exposure to unsafe position \\
\hline $\mathrm{R}_{29}$ & & Lack of alertness of the workers \\
\hline $\mathrm{R}_{30}$ & \multirow{4}{*}{ Job factors } & Inadequate job orientation/induction courses \\
\hline $\mathrm{R}_{31}$ & & Improper storage of materials \\
\hline $\mathrm{R}_{32}$ & & Unrealistic risk assessment \\
\hline $\mathrm{R}_{33}$ & & Unrealistic hazard analysis \\
\hline
\end{tabular}

In this study, a method named Risk Critical Point (RCP) is used for assessing risk events. In the assessment phase, because of the vagueness and uncertainty in risk qualifying issues, there is the need for expert opinions and expert interpretations of fuzzy input data which is uncertain.

To begin with, the RCP method is a new framework that consists of three indexes that are defined to assess risk events consisting of probability, impact and the new index namely Safety Performance Index (SPI) which measures the capability of an appropriate response to reduce or limit the effect of an event after its occurrence with regard to safety performance in project. It depends on the extent to which an organization is equipped at the time to act on an identified risk without the need for any additional equipment. For example, having a great team of experts in the field of excavation may mitigate the effect and probability of related threats. Conversely, if there is a lack of capable experts, the organization may incur additional costs when improving the project's safety performance.

In this method, a numerical risk critical point is defined with the aid of three mentioned indexes that leads to a risk zoning by determining the superior limit of probability and impact adjusted by SPI. The following steps will be implemented through the RCP method: 


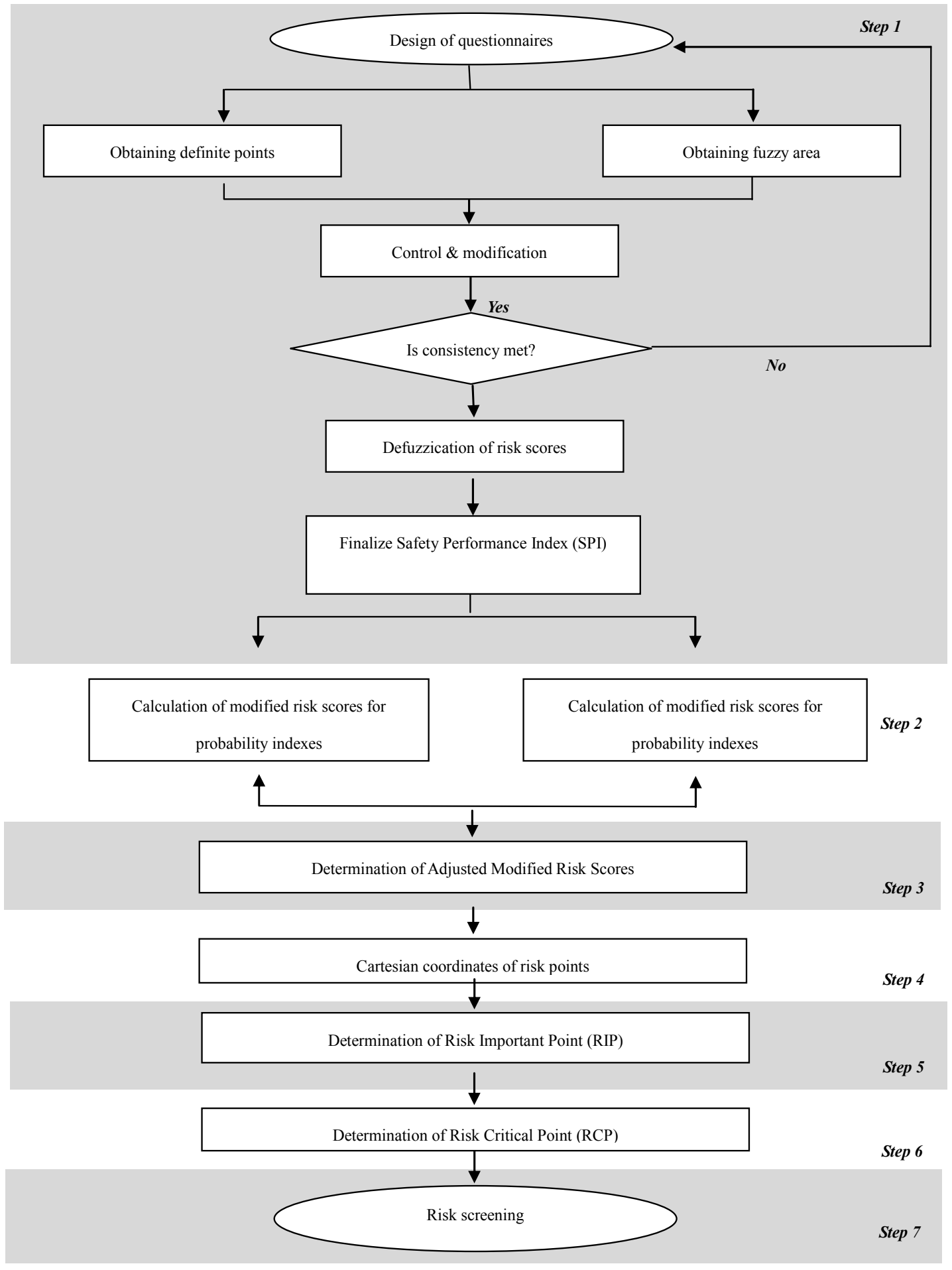

Figure 1. Flow-diagram of processes applied in the RCP method.

\subsection{Step 1: Obtaining Risk Indexes via Questionnaires}

In the first step, two questionnaire forms are used to elicit information about probability, impact and also
SPI indexes. First questionnaire will be used for definite numbers and the second one for interval numbers. In these questionnaires a five-point bipolar Likert scale is used to define the importance of evaluation criteria and rate the alternatives as presented in Table 3. 
Table 3. Interpretation of linguistic terms used in the five-point scale

\begin{tabular}{clll}
\hline Rating & Linguistic Value & \multicolumn{1}{c}{ Probability } & \multicolumn{1}{c}{ Impact } \\
\hline 1 & Very Low & Very unlikely to happen & No impact \\
\hline 2 & Low & Occurrence is unlikely & No critical impact \\
\hline 3 & Mediocre & Likely to occur & No substantial impact \\
\hline 4 & High & Very likely to occur & Certain impact \\
\hline 5 & Very High & Occurrence is almost inevitable & High impact \\
\hline
\end{tabular}

It is obvious that we often face the difficulty of lacking precise information to assess the risk of a component in an uncertain environment. In order to overcome this problem, fuzzy numbers have been used to represent the fuzziness of evaluating values in fuzzy risk analysis problems. The fuzzy set theory was introduced by Zadeh (1965) to solve problems involving the absence of sharply defined criteria. This theory has been applied in a variety of fields since its introduction (Lee, 2009) which seems to be the appropriate approach to model human experts' reasoning processes much better than conventional expert systems. Despite the many advantages of fuzzy set theory, it is very important to use a well-defined boundary.

Lee and Chen (2008) introduced a method for ranking fuzzy numbers which considered different shapes and different deviations when dealing with fuzzy risk analysis problems.

In this study, we present a new method for ranking fuzzy numbers based on expert claims which are the most trustworthy references in the case of risk weighting. The proposed method considers specific triangular shapes for each risk regarding each expert interviewee. Once the definite numbers have been elicited by questionnaires, they undergo a defuzzification process to determine a crisp or point estimate of a fuzzy number. It should be noted that there is no predetermined scale for the process of defuzzification. So this process is flexible and can be dictated by the expert assumptions and requirements in such a manner that, for every risk index in every assessment case, different membership functions can be assigned. Figure 2 shows an instance of fuzzy membership function of probability index used for the first four identified risks.

In this study, the triangular membership function has been utilized in the defuzzification process as well. Eq. (1) shows the center of area method formula (COA) in which a triangular fuzzy number shown by $\mathrm{M}(\mathrm{a}, \mathrm{b}, \mathrm{c})$ can be calculated and commonly accepted for the fuzzy expert system development (Driankov et al., 1996).

$$
M=\frac{((c-a)+(b-a))}{3+a}
$$

Safety performance index $\left(\operatorname{SPI}\left(R_{i}\right)\right)$ will be calculated by using Eq. (2) in which the $x_{i}$ is the defuzzifier number achieved by the safety performance part of the questionnaires.

$$
S P I=x_{i} / 5
$$

\subsection{Step 2: Modified Risk Impact and Probability Indexes}

In this step, the modified $M I$ and $M P$ of each point $R P\left(y_{i}, z_{i}\right)$ are determined according to Eq. (3), Eq. (4) in order to modify them in between the $[0,1]$ interval.

$$
\begin{aligned}
& M I_{i}=\left[\left(y_{i}-y_{i(\min )}\right) /\left(y_{i(\max )}-y_{i(\min )}\right)\right] \\
& M I_{p}=\left[\left(z_{i}-z_{i(\min )}\right) /\left(z_{i(\max )}-z_{i(\min )}\right)\right]
\end{aligned}
$$

Where $y_{i(\min )}$ and $y_{i(\max )}$ are the minimum and ma-

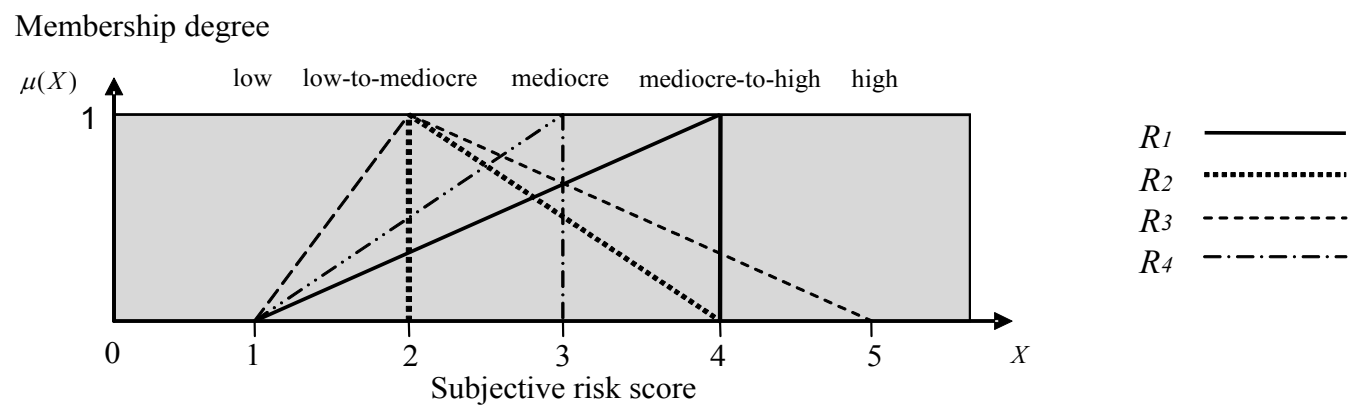

Figure 2. An instance of fuzzy membership function for four subjective risk scoring. 
ximum $I$, also, $z_{i(\min )}$ and $z_{i(\max )}$ are the minimum and maximum $P$ respectively.

\subsection{Step 3: Determination of Adjusted-Modified Risk Scores}

As mentioned earlier the aim of RCP method is to consider three indexes for risk assessment which are consisted of probability, impact and SPI of each identified safety risk $(R i)$.Thus, in this step adjusted scores are calculated for both modified impact $M I_{i}$ andprobability $M P_{i}$ indexes $\left(S\left(M I_{i}, R i\right)\right.$ and $\left.S\left(M P_{i}, R i\right)\right)$. These adjusted-modified scores can be calculated using Eq. (5), Eq. (6), the safety performance index SPI(Ri) of each risk which is obtained from first step is applied to calculate the scores.

$S\left(M P_{i}, R i\right)$ : the adjusted-modified probability of safety risk after considering the existing condition of the project's organizational capability and measurement in order to prevent it from happening or increasing the safety probability of that risk.

$S\left(M I_{i}, R i\right)$ : the adjusted-modified impact of safety risk after considering the existing condition of project's organizational capability and measurement in order to prevent it from happening or increasing the safety impact of that risk.

$M I_{i}$ : Modified impact score of the risk Ri $i=1,2$, $\cdots, m$ (the number of total identified safety risk)

$M I_{i}:$ modified probability score of the risk $R i$ $S\left(M I_{i}, R i\right)=M S_{I}=M I_{i} \times S P I(R i)$

$$
S\left(M P_{i}, R i\right)=M S_{P}=M P_{i} \times S P I(R i)
$$

\subsection{Step 4: Finding Risk Points}

The adjusted-modified scores comprise a number of risk points $R P(M S I, M S P)$ on the Impact-Probability $(I-P)$ coordinate axes. Therefore, the Cartesian coordinates of each point for each risk $R i$ are defined as Eq. (7)

$$
R P\left(M S_{I}, M S_{P}\right)=\left(M I_{i}\right) \times S P I(R i),=M P_{i} \times S P I(R i)
$$

\subsection{Step 5: Determination of Important Risk Point (RIP)}

To determine the important risk point $\left(\mathrm{RIP}=\left(\left(M S_{I}\right)_{R I P}\right)\right.$, $\left.\left(M S_{P}\right)_{R I P}\right)$ the column derived from multiplying the $M I_{i}$ columns has been determined first; then, the risk point which has a maximum multiplied score will be highlighted as an important risk point

\subsection{Step 6: Determination of Risk Critical Point}

In order to find the risk critical point, we use the $80 / 20$ rule known as the Pareto principle which states that $20 \%$ of the risk makes up $80 \%$ of the hazards, the $80 \%$ amount of considered risk scores will lead to identifying the risk critical point of this method $(\mathrm{RCP}=$ $\left.\left(\left(M S_{I}\right)_{R C P}\right),\left(M S_{P}\right)_{R C P}\right)$ using Eq. (8), Eq. (9).

$$
\left(M S_{I}\right)_{R C P}=80 \% \times\left(M S_{I}\right)_{R I P}
$$

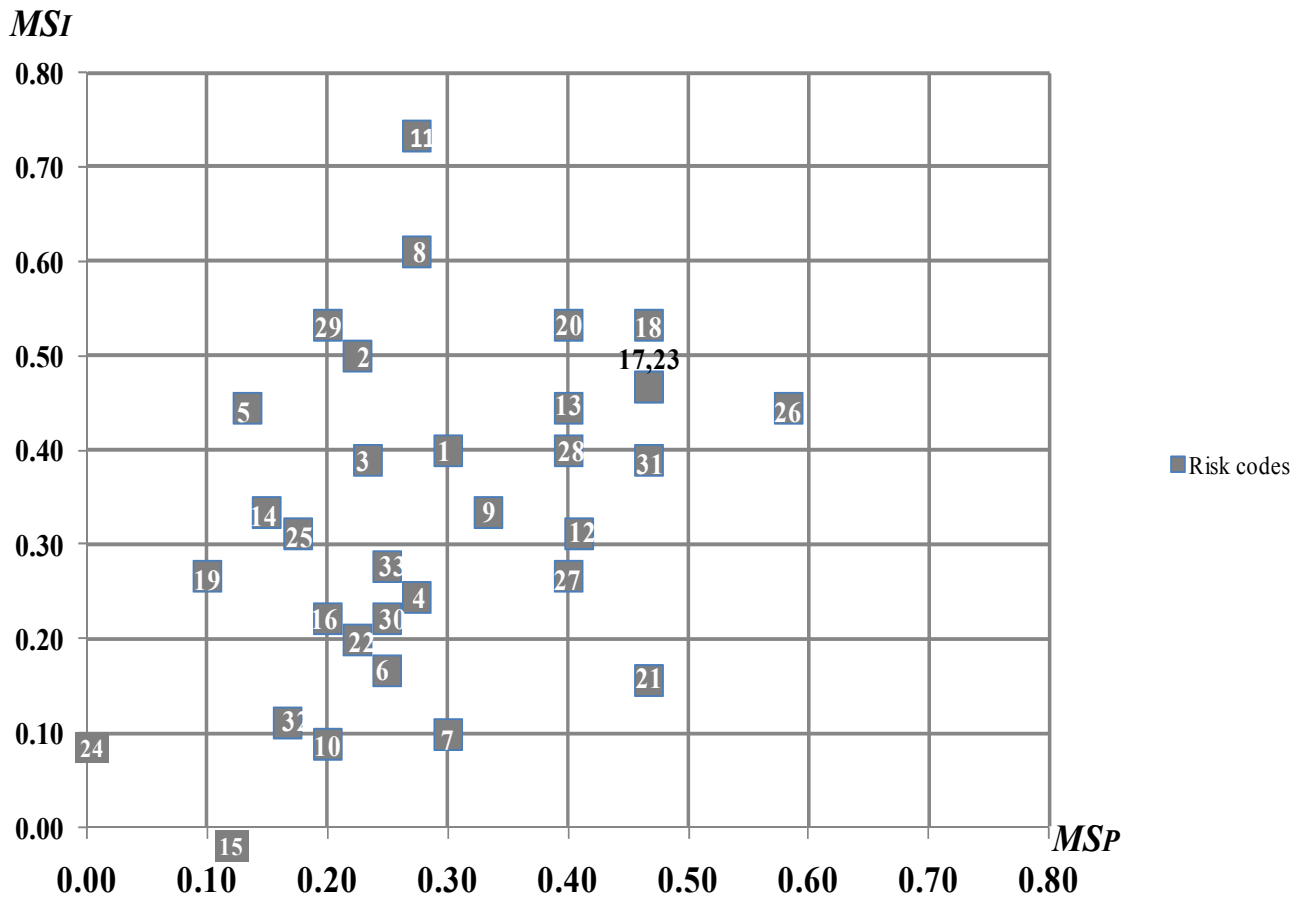

Figure 3. Scattered diagram. 
MSI

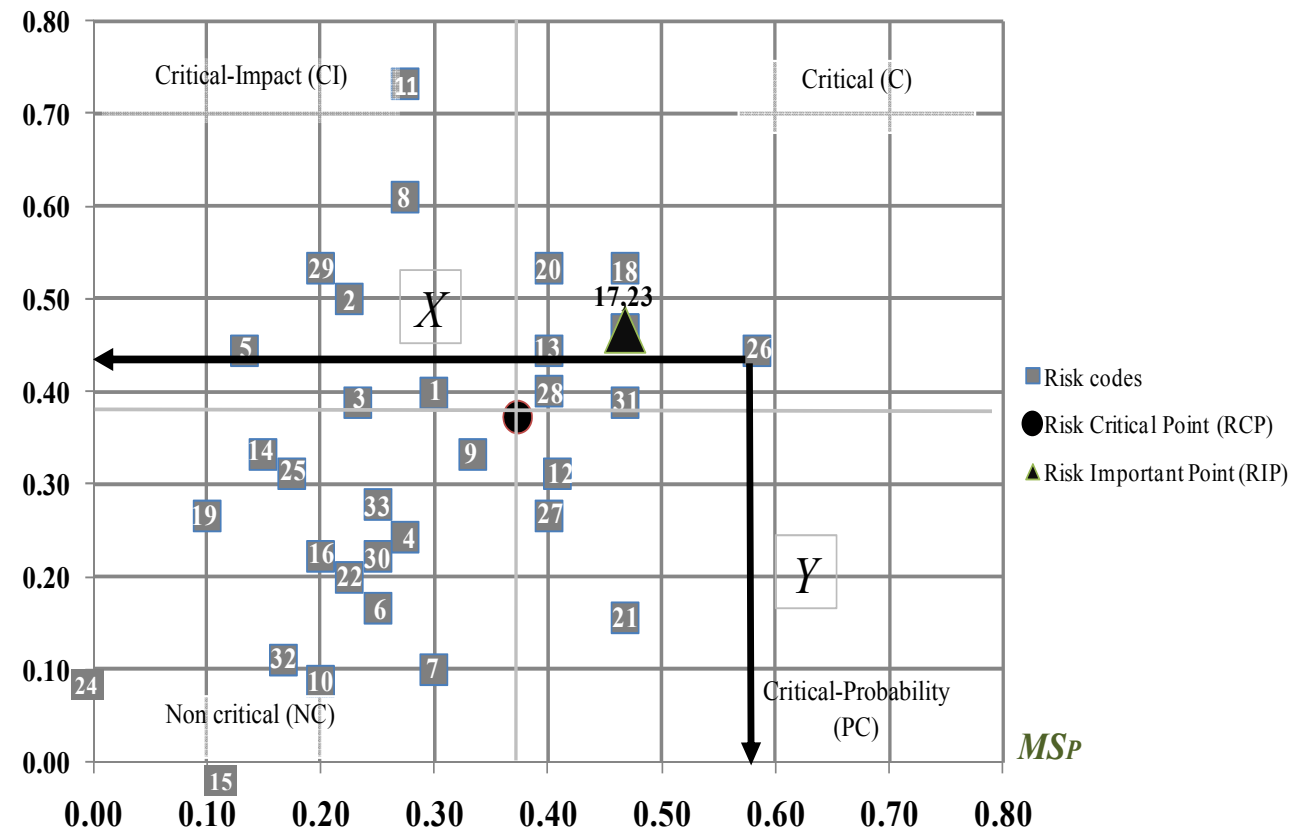

Figure 4. The four quarter zones defined by risk critical point.

\section{MSI}

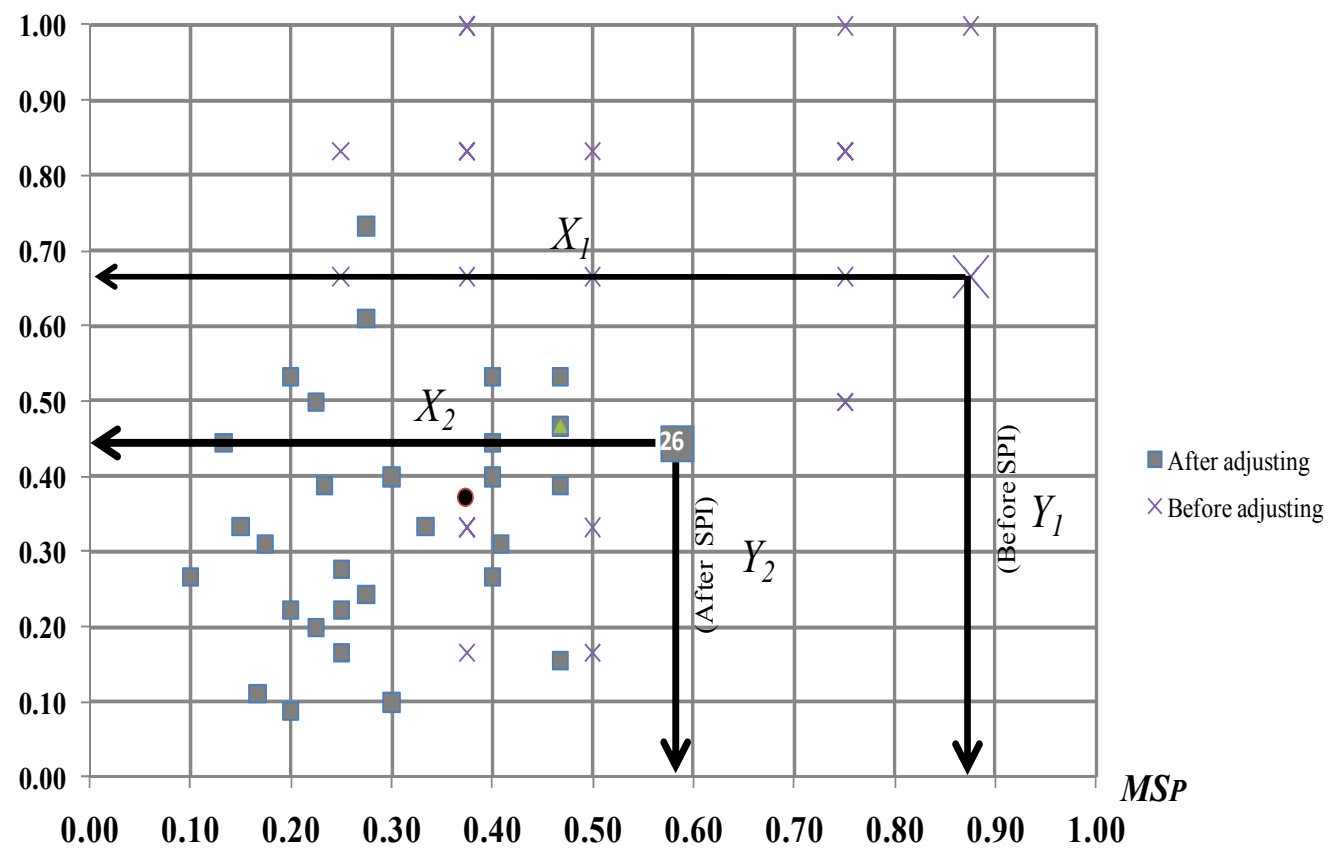

Figure 5. Total measurement comparison between before and after considering safety performance index (SPI).

$$
\left(M S_{P}\right)_{R C P}=80 \% \times\left(M S_{P}\right)_{R I P}
$$

\subsection{Step 7: Risk Screening}

The calculated RCP creates four quarter zones in the coordinate area so that they have a new coordinating center that is named the 'critical point.' These quarters are respectively recognized as critical, critical probability, critical impact, and non-critical zones in an anticlockwise order. 


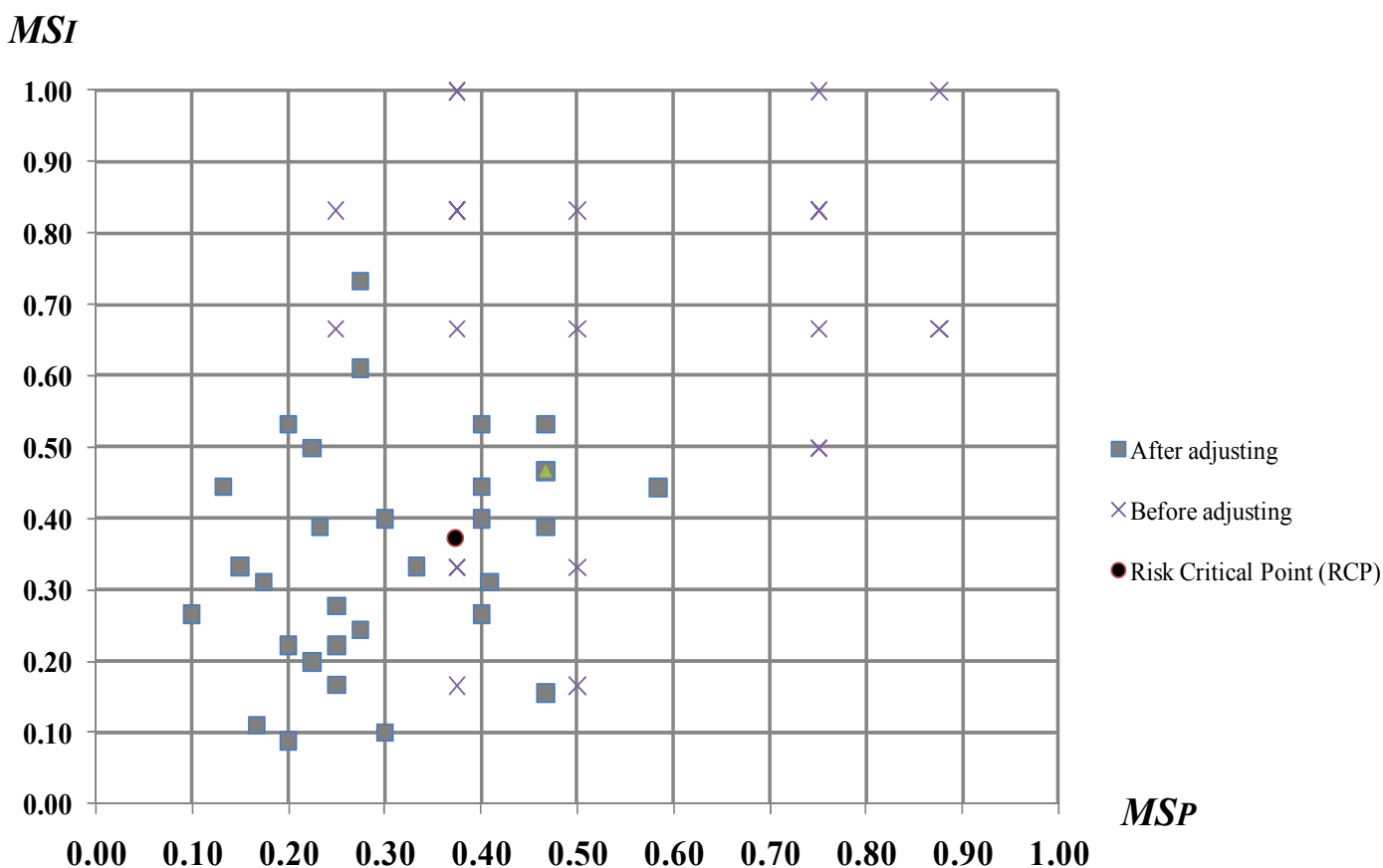

Figure 6. Comparison of modified risk scores before and after adjustment.

Table 4. Overall profile of personnel contributing in the required judgments

\begin{tabular}{ccc}
\hline Category & $\begin{array}{c}\text { Respondents Number } \\
\text { Year of experience }\end{array}$ \\
\hline$>20$ years & 12 & \\
\hline $10-20$ years & 8 & 20.00 \\
\hline $5-10$ years & 7 & 23.33 \\
\hline$<5$ years & 3 & 10.00 \\
\hline & Role & 16.67 \\
\hline Owner & 5 & 33.33 \\
\hline Designer & 10 & 36.67 \\
\hline Contractor & 11 & 13.33 \\
\hline Design manager & 4 & 20.00 \\
\hline & & 30.00 \\
\hline Project Managers & Position & 50.00 \\
\hline Department Heads & 6 & \\
\hline Architect/Engineers & 9 & \\
\hline & 15 & \\
\hline
\end{tabular}

\section{METHOD TESTING}

The level of uncertainty associated with a system is proportional to its complexity, which arises as a result of vaguely known relationships among various entities, and randomness in the mechanisms governing the domain. In Iran, with the low informatization level of the construction domain, the awareness of risk management falls behind. In this section, the case of the Milad tower is provided to illustrate a real-world application of the RCP method.
In the following, the eight successive steps proposed for RCP model will be utilized:

Steps 1: In the first step, a questionnaire survey forms had been distributed to construction professionals. The completed responses were collected either personally, or received through regular postal mails, e-mails, and faxes. Table 4 summarizes the respondents' profiles.

In order to ensure subjectivity of the responses, the definite and intervallic scores for impact and probability 
of each risk and safety performance were elicited from two separate questionnaires. This led to fuzzy scores for risk indexes represented in triangular membership functions. The fuzzy numbers were then converted to diffuzifier numbers for impact and probability indexes by using Eq (1) and to obtain SPI by using Eq. (1) and Eq. (2) in turn. Final responses to the two questionnaires were sent to stakeholders and are shown in Figures 5 and 6 . The figures show that one questionnaire has been designed to acquire the peak point (Table 5) of triangu- lar membership function, and the other to obtain an interval of inferior and superior points (Table 6). When the returned peak point of the first questionnaire is laid outside the interval in the second questionnaire, an inconsistency occurs. On these occasions, the interval limit is extended so that it covers the peak point in one of its two edges. Then, the mean value between inferior and superior points of the new interval is given as the new peak point to be considered in the fuzzy logic calculations.

Table 5. Final result of questionnaire used to obtain definite points

\begin{tabular}{|c|c|c|c|c|c|c|c|c|c|c|c|c|c|c|c|}
\hline \multirow{2}{*}{$\begin{array}{c}\text { Risk Codes } \\
\mathrm{R}_{1}\end{array}$} & \multicolumn{5}{|c|}{ Risk probability } & \multicolumn{5}{|c|}{ Risk impact } & \multicolumn{5}{|c|}{ Risk safety performance } \\
\hline & 1 & 2 & 3 & 4 & 5 & 1 & 2 & 3 & 4 & 5 & 1 & 2 & 3 & 4 & 5 \\
\hline $\mathrm{R}_{2}$ & 1 & 2 & 3 & 4 & 5 & 1 & 2 & 3 & 4 & 5 & 1 & 2 & 3 & 4 & 5 \\
\hline $\mathrm{R}_{3}$ & 1 & 2 & 3 & 4 & 5 & 1 & 2 & 3 & 4 & 5 & 1 & 2 & 3 & 4 & 5 \\
\hline $\mathrm{R}_{4}$ & 1 & 2 & 3 & 4 & 5 & 1 & 2 & 3 & 4 & 5 & 1 & 2 & 3 & 4 & 5 \\
\hline $\mathrm{R}_{5}$ & 1 & 2 & 3 & 4 & 5 & 1 & 2 & 3 & 4 & 5 & 1 & 2 & 3 & 4 & 5 \\
\hline $\mathrm{R}_{6}$ & 1 & 2 & 3 & 4 & 5 & 1 & 2 & 3 & 4 & 5 & 1 & 2 & 3 & 4 & 5 \\
\hline $\mathrm{R}_{7}$ & 1 & 2 & 3 & 4 & 5 & 1 & 2 & 3 & 4 & 5 & 1 & 2 & 3 & 4 & 5 \\
\hline $\mathrm{R}_{8}$ & 1 & 2 & 3 & 4 & 5 & 1 & 2 & 3 & 4 & 5 & 1 & 2 & 3 & 4 & 5 \\
\hline $\mathrm{R}_{9}$ & 1 & 2 & 3 & 4 & 5 & 1 & 2 & 3 & 4 & 5 & 1 & 2 & 3 & 4 & 5 \\
\hline $\mathrm{R}_{10}$ & 1 & 2 & 3 & 4 & 5 & 1 & 2 & 3 & 4 & 5 & 1 & 2 & 3 & 4 & 5 \\
\hline $\mathrm{R}_{11}$ & 1 & 2 & 3 & 4 & 5 & 1 & 2 & 3 & 4 & 5 & 1 & 2 & 3 & 4 & 5 \\
\hline $\mathrm{R}_{12}$ & 1 & 2 & 3 & 4 & 5 & 1 & 2 & 3 & 4 & 5 & 1 & 2 & 3 & 4 & 5 \\
\hline $\mathrm{R}_{13}$ & 1 & 2 & 3 & 4 & 5 & 1 & 2 & 3 & 4 & 5 & 1 & 2 & 3 & 4 & 5 \\
\hline $\mathrm{R}_{14}$ & 1 & 2 & 3 & 4 & 5 & 1 & 2 & 3 & 4 & 5 & 1 & 2 & 3 & 4 & 5 \\
\hline $\mathrm{R}_{15}$ & 1 & 2 & 3 & 4 & 5 & 1 & 2 & 3 & 4 & 5 & 1 & 2 & 3 & 4 & 5 \\
\hline $\mathrm{R}_{16}$ & 1 & 2 & 3 & 4 & 5 & 1 & 2 & 3 & 4 & 5 & 1 & 2 & 3 & 4 & 5 \\
\hline $\mathrm{R}_{17}$ & 1 & 2 & 3 & 4 & 5 & 1 & 2 & 3 & 4 & 5 & 1 & 2 & 3 & 4 & 5 \\
\hline $\mathrm{R}_{18}$ & 1 & 2 & 3 & 4 & 5 & 1 & 2 & 3 & 4 & 5 & 1 & 2 & 3 & 4 & 5 \\
\hline $\mathrm{R}_{19}$ & 1 & 2 & 3 & 4 & 5 & 1 & 2 & 3 & 4 & 5 & 1 & 2 & 3 & 4 & 5 \\
\hline $\mathrm{R}_{20}$ & 1 & 2 & 3 & 4 & 5 & 1 & 2 & 3 & 4 & 5 & 1 & 2 & 3 & 4 & 5 \\
\hline $\mathrm{R}_{21}$ & 1 & 2 & 3 & 4 & 5 & 1 & 2 & 3 & 4 & 5 & 1 & 2 & 3 & 4 & 5 \\
\hline $\mathrm{R}_{22}$ & 1 & 2 & 3 & 4 & 5 & 1 & 2 & 3 & 4 & 5 & 1 & 2 & 3 & 4 & 5 \\
\hline $\mathrm{R}_{23}$ & 1 & 2 & 3 & 4 & 5 & 1 & 2 & 3 & 4 & 5 & 1 & 2 & 3 & 4 & 5 \\
\hline $\mathrm{R}_{24}$ & 1 & 2 & 3 & 4 & 5 & 1 & 2 & 3 & 4 & 5 & 1 & 2 & 3 & 4 & 5 \\
\hline $\mathrm{R}_{25}$ & 1 & 2 & 3 & 4 & 5 & 1 & 2 & 3 & 4 & 5 & 1 & 2 & 3 & 4 & 5 \\
\hline $\mathrm{R}_{26}$ & 1 & 2 & 3 & 4 & 5 & 1 & 2 & 3 & 4 & 5 & 1 & 2 & 3 & 4 & 5 \\
\hline $\mathrm{R}_{27}$ & 1 & 2 & 3 & 4 & 5 & 1 & 2 & 3 & 4 & 5 & 1 & 2 & 3 & 4 & 5 \\
\hline $\mathrm{R}_{28}$ & 1 & 2 & 3 & 4 & 5 & 1 & 2 & 3 & 4 & 5 & 1 & 2 & 3 & 4 & 5 \\
\hline $\mathrm{R}_{29}$ & 1 & 2 & 3 & 4 & 5 & 1 & 2 & 3 & 4 & 5 & 1 & 2 & 3 & 4 & 5 \\
\hline $\mathrm{R}_{30}$ & 1 & 2 & 3 & 4 & 5 & 1 & 2 & 3 & 4 & 5 & 1 & 2 & 3 & 4 & 5 \\
\hline $\mathrm{R}_{31}$ & 1 & 2 & 3 & 4 & 5 & 1 & 2 & 3 & 4 & 5 & 1 & 2 & 3 & 4 & 5 \\
\hline $\mathrm{R}_{32}$ & 1 & 2 & 3 & 4 & 5 & 1 & 2 & 3 & 4 & 5 & 1 & 2 & 3 & 4 & 5 \\
\hline $\mathrm{R}_{33}$ & 1 & 2 & 3 & 4 & 5 & 1 & 2 & 3 & 4 & 5 & 1 & 2 & 3 & 4 & 5 \\
\hline
\end{tabular}


Steps 2: In the second step, modified numbers are identified for components $y i$ and $z i$ of each $R P\left(y_{i}, z_{i}\right)$ according to Eq. (3) and Eq. (4) and have been shown in the specified column of Table 7 . This table shows the steps taken in this stage of calculation for risks. The peak $b$, inferior $a$, and superior $c$ scores have been put in Eq. (1) and the defuzifier numbers $M$ have been obtained. Then using Eq. (2), the safety performance index $S P I(R i)$ for each risk has been calculated.
Step 3: The safety performance index $S P I(R i)$ of risk is used in order to calculate the risk adjusted-modified scores $\left(S\left(M I_{i}, R i\right)\right.$ and $\left.S\left(M P_{i}, R i\right)\right)$ by using Eq. (5) and Eq. (6) (Table 7).

Step 4: In this step, the risk point $R P(M S I, M S P)$ scores which are defined as Eq. (7) are calculated (Table 7) and have been shown on the Impact-Probability $(I-P)$ Cartesian coordinate axes (Figure 3 ) with specific rectangular

Table 6. An instance of questionnaire for obtaining fuzzy area

\begin{tabular}{|c|c|c|c|c|c|c|c|c|c|c|c|c|c|c|c|}
\hline \multirow{2}{*}{$\frac{\text { Risk Codes }}{\mathrm{R}_{1}}$} & \multicolumn{5}{|c|}{ Risk probability } & \multicolumn{5}{|c|}{ Risk impact } & \multicolumn{5}{|c|}{ Risk safety performance } \\
\hline & 1 & 2 & 3 & 4 & 5 & 1 & 2 & 3 & 4 & 5 & 1 & 2 & 3 & 4 & 5 \\
\hline $\mathrm{R}_{2}$ & 1 & 2 & 3 & 4 & 5 & 1 & 2 & 3 & 4 & 5 & 1 & 2 & 3 & 4 & 5 \\
\hline $\mathrm{R}_{3}$ & 1 & 2 & 3 & 4 & 5 & 1 & 2 & 3 & 4 & 5 & 1 & 2 & 3 & 4 & 5 \\
\hline $\mathrm{R}_{4}$ & 1 & 2 & 3 & 4 & 5 & 1 & 2 & 3 & 4 & 5 & 1 & 2 & 3 & 4 & 5 \\
\hline $\mathrm{R}_{5}$ & 1 & 2 & 3 & 4 & 5 & 1 & 2 & 3 & 4 & 5 & 1 & 2 & 3 & 4 & 5 \\
\hline $\mathrm{R}_{6}$ & 1 & 2 & 3 & 4 & 5 & 1 & 2 & 3 & 4 & 5 & 1 & 2 & 3 & 4 & 5 \\
\hline $\mathrm{R}_{7}$ & 1 & 2 & 3 & 4 & 5 & 1 & 2 & 3 & 4 & 5 & 1 & 2 & 3 & 4 & 5 \\
\hline $\mathrm{R}_{8}$ & 1 & 2 & 3 & 4 & 5 & 1 & 2 & 3 & 4 & 5 & 1 & 2 & 3 & 4 & 5 \\
\hline $\mathrm{R}_{9}$ & 1 & 2 & 3 & 4 & 5 & 1 & 2 & 3 & 4 & 5 & 1 & 2 & 3 & 4 & 5 \\
\hline $\mathrm{R}_{10}$ & 1 & 2 & 3 & 4 & 5 & 1 & 2 & 3 & 4 & 5 & 1 & 2 & 3 & 4 & 5 \\
\hline $\mathrm{R}_{11}$ & 1 & 2 & 3 & 4 & 5 & 1 & 2 & 3 & 4 & 5 & 1 & 2 & 3 & 4 & 5 \\
\hline $\mathrm{R}_{12}$ & 1 & 2 & 3 & 4 & 5 & 1 & 2 & 3 & 4 & 5 & 1 & 2 & 3 & 4 & 5 \\
\hline $\mathrm{R}_{13}$ & 1 & 2 & 3 & 4 & 5 & 1 & 2 & 3 & 4 & 5 & 1 & 2 & 3 & 4 & 5 \\
\hline $\mathrm{R}_{14}$ & 1 & 2 & 3 & 4 & 5 & 1 & 2 & 3 & 4 & 5 & 1 & 2 & 3 & 4 & 5 \\
\hline $\mathrm{R}_{15}$ & 1 & 2 & 3 & 4 & 5 & 1 & 2 & 3 & 4 & 5 & 1 & 2 & 3 & 4 & 5 \\
\hline $\mathrm{R}_{16}$ & 1 & 2 & 3 & 4 & 5 & 1 & 2 & 3 & 4 & 5 & 1 & 2 & 3 & 4 & 5 \\
\hline $\mathrm{R}_{17}$ & 1 & 2 & 3 & 4 & 5 & 1 & 2 & 3 & 4 & 5 & 1 & 2 & 3 & 4 & 5 \\
\hline $\mathrm{R}_{18}$ & 1 & 2 & 3 & 4 & 5 & 1 & 2 & 3 & 4 & 5 & 1 & 2 & 3 & 4 & 5 \\
\hline $\mathrm{R}_{19}$ & 1 & 2 & 3 & 4 & 5 & 1 & 2 & 3 & 4 & 5 & 1 & 2 & 3 & 4 & 5 \\
\hline $\mathrm{R}_{20}$ & 1 & 2 & 3 & 4 & 5 & 1 & 2 & 3 & 4 & 5 & 1 & 2 & 3 & 4 & 5 \\
\hline $\mathrm{R}_{21}$ & 1 & 2 & 3 & 4 & 5 & 1 & 2 & 3 & 4 & 5 & 1 & 2 & 3 & 4 & 5 \\
\hline $\mathrm{R}_{22}$ & 1 & 2 & 3 & 4 & 5 & 1 & 2 & 3 & 4 & 5 & 1 & 2 & 3 & 4 & 5 \\
\hline $\mathrm{R}_{23}$ & 1 & 2 & 3 & 4 & 5 & 1 & 2 & 3 & 4 & 5 & 1 & 2 & 3 & 4 & 5 \\
\hline $\mathrm{R}_{24}$ & 1 & 2 & 3 & 4 & 5 & 1 & 2 & 3 & 4 & 5 & 1 & 2 & 3 & 4 & 5 \\
\hline $\mathrm{R}_{25}$ & 1 & 2 & 3 & 4 & 5 & 1 & 2 & 3 & 4 & 5 & 1 & 2 & 3 & 4 & 5 \\
\hline $\mathrm{R}_{26}$ & 1 & 2 & 3 & 4 & 5 & 1 & 2 & 3 & 4 & 5 & 1 & 2 & 3 & 4 & 5 \\
\hline $\mathrm{R}_{27}$ & 1 & 2 & 3 & 4 & 5 & 1 & 2 & 3 & 4 & 5 & 1 & 2 & 3 & 4 & 5 \\
\hline $\mathrm{R}_{28}$ & 1 & 2 & 3 & 4 & 5 & 1 & 2 & 3 & 4 & 5 & 1 & 2 & 3 & 4 & 5 \\
\hline $\mathrm{R}_{29}$ & 1 & 2 & 3 & 4 & 5 & 1 & 2 & 3 & 4 & 5 & 1 & 2 & 3 & 4 & 5 \\
\hline $\mathrm{R}_{30}$ & 1 & 2 & 3 & 4 & 5 & 1 & 2 & 3 & 4 & 5 & 1 & 2 & 3 & 4 & 5 \\
\hline $\mathrm{R}_{31}$ & 1 & 2 & 3 & 4 & 5 & 1 & 2 & 3 & 4 & 5 & 1 & 2 & 3 & 4 & 5 \\
\hline $\mathrm{R}_{32}$ & 1 & 2 & 3 & 4 & 5 & 1 & 2 & 3 & 4 & 5 & 1 & 2 & 3 & 4 & 5 \\
\hline $\mathrm{R}_{33}$ & 1 & 2 & 3 & 4 & 5 & 1 & 2 & 3 & 4 & 5 & 1 & 2 & 3 & 4 & 5 \\
\hline
\end{tabular}


Soltanmohammadi, Saberi, Yoon, Soltanmohammadi, and Pazhoheshfar: Industrial Engineering \& Management Systems Vol 14, No 3, September 2015, pp.221-235, (C) 2015 KIIE

shapes.

Step 5: In the fifth step, the risk important point $(\mathrm{RIP}=$ $\left.\left(\left(M S_{I}\right)_{R I P}\right),\left(M S_{P}\right)_{R I P}\right)$ which is achieved by using the multiplied column (Table 8 ) has been specified in a tri- angular shape (Figure 4).

Step 6: In the sixth step, the risk critical point of the components ( $R C P I$ and $R C P P$ ) is obtained by using Eq. (8) and Eq. (9). In Figure 4, the Cartesian coordinate of

Table 7. Calculation of the adjusted-modified risk scores

\begin{tabular}{|c|c|c|c|c|c|c|c|c|c|c|c|c|c|c|c|c|c|}
\hline \multirow[b]{2}{*}{ 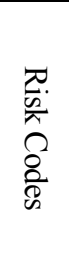 } & \multicolumn{5}{|c|}{ Risk probability } & \multicolumn{5}{|c|}{ Risk impact } & \multicolumn{5}{|c|}{ Safety performance } & \multicolumn{2}{|c|}{$\begin{array}{l}\text { Adjusted modified } \\
\text { scores }\end{array}$} \\
\hline & 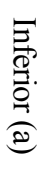 & $\frac{\vec{D}}{\stackrel{2}{\hat{C}}}$ & 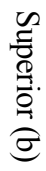 & $\unlhd$ & 尔 & 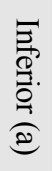 & 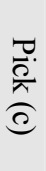 & 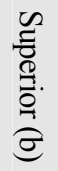 & 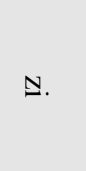 & 名 & 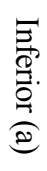 & $\frac{\overrightarrow{0}}{\stackrel{2}{\hat{C}}}$ & 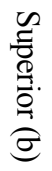 & $凶$. & 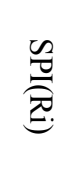 & 3 & ๘ \\
\hline $\mathrm{R}_{1}$ & 1 & 4 & 4 & 3.00 & 0.50 & 3 & 4 & 5 & 4.00 & 0.67 & 2 & 2 & 5 & 3.00 & 0.60 & 0.30 & 0.40 \\
\hline $\mathrm{R}_{2}$ & 2 & 2 & 4 & 2.67 & 0.37 & 4 & 4 & 5 & 4.33 & 0.83 & 2 & 3 & 4 & 3.00 & 0.60 & 0.22 & 0.50 \\
\hline $\mathrm{R}_{3}$ & 1 & 3 & 5 & 3.00 & 0.50 & 3 & 5 & 5 & 4.33 & 0.83 & 2 & 2 & 3 & 2.33 & 0.47 & 0.23 & 0.39 \\
\hline $\mathrm{R}_{4}$ & 2 & 3 & 3 & 2.67 & 0.37 & 2 & 3 & 5 & 3.33 & 0.33 & 3 & 3 & 5 & 3.67 & 0.73 & 0.27 & 0.24 \\
\hline $\mathrm{R}_{5}$ & 1 & 3 & 3 & 2.33 & 0.25 & 4 & 4 & 5 & 4.33 & 0.83 & 2 & 2 & 4 & 2.67 & 0.53 & 0.13 & 0.44 \\
\hline $\mathrm{R}_{6}$ & 3 & 3 & 5 & 3.67 & 0.75 & 3 & 4 & 4 & 3.67 & 0.50 & 1 & 2 & 2 & 1.67 & 0.33 & 0.25 & 0.17 \\
\hline $\mathrm{R}_{7}$ & 2 & 2 & 5 & 3.00 & 0.50 & 2 & 2 & 5 & 3.00 & 0.17 & 1 & 4 & 4 & 3.00 & 0.60 & 0.30 & 0.10 \\
\hline $\mathrm{R}_{8}$ & 2 & 3 & 3 & 2.67 & 0.37 & 3 & 5 & 5 & 4.33 & 0.83 & 3 & 3 & 5 & 3.67 & 0.73 & 0.27 & 0.61 \\
\hline $\mathrm{R}_{9}$ & 4 & 4 & 5 & 4.33 & 1.00 & 4 & 5 & 5 & 4.67 & 1.00 & 1 & 2 & 2 & 1.67 & 0.33 & 0.33 & 0.33 \\
\hline $\mathrm{R}_{10}$ & 2 & 2 & 4 & 2.67 & 0.37 & 2 & 3 & 4 & 3.00 & 0.17 & 1 & 3 & 4 & 2.67 & 0.53 & 0.20 & 0.09 \\
\hline $\mathrm{R}_{11}$ & 2 & 2 & 4 & 2.67 & 0.37 & 4 & 5 & 5 & 4.67 & 1.00 & 3 & 3 & 5 & 3.67 & 0.73 & 0.27 & 0.73 \\
\hline $\mathrm{R}_{12}$ & 3 & 4 & 5 & 4.00 & 0.88 & 3 & 4 & 5 & 4.00 & 0.67 & 1 & 2 & 4 & 2.33 & 0.47 & 0.41 & 0.31 \\
\hline $\mathrm{R}_{13}$ & 3 & 3 & 5 & 3.67 & 0.75 & 4 & 4 & 5 & 4.33 & 0.83 & 2 & 2 & 4 & 2.67 & 0.53 & 0.40 & 0.44 \\
\hline $\mathrm{R}_{14}$ & 2 & 2 & 4 & 2.67 & 0.37 & 3 & 5 & 5 & 4.33 & 0.83 & 1 & 2 & 3 & 2.00 & 0.40 & 0.15 & 0.33 \\
\hline $\mathrm{R}_{15}$ & 2 & 3 & 3 & 2.67 & 0.37 & 1 & 3 & 4 & 2.67 & 0.00 & 1 & 2 & 2 & 1.67 & 0.33 & 0.12 & 0.00 \\
\hline $\mathrm{R}_{16}$ & 3 & 3 & 5 & 3.67 & 0.75 & 4 & 4 & 5 & 4.33 & 0.83 & 1 & 1 & 2 & 1.33 & 0.27 & 0.20 & 0.22 \\
\hline $\mathrm{R}_{17}$ & 4 & 4 & 5 & 4.33 & 1.00 & 4 & 5 & 5 & 4.67 & 1.00 & 1 & 3 & 3 & 2.33 & 0.47 & 0.47 & 0.47 \\
\hline $\mathrm{R}_{18}$ & 3 & 4 & 5 & 4.00 & 0.88 & 4 & 5 & 5 & 4.67 & 1.00 & 2 & 2 & 4 & 2.67 & 0.53 & 0.47 & 0.53 \\
\hline $\mathrm{R}_{19}$ & 2 & 2 & 3 & 2.33 & 0.25 & 3 & 4 & 5 & 4.00 & 0.67 & 1 & 2 & 3 & 2.00 & 0.40 & 0.10 & 0.27 \\
\hline $\mathrm{R}_{20}$ & 3 & 3 & 5 & 3.67 & 0.75 & 4 & 5 & 5 & 4.67 & 1.00 & 2 & 2 & 4 & 2.67 & 0.53 & 0.40 & 0.53 \\
\hline $\mathrm{R}_{21}$ & 4 & 4 & 5 & 4.33 & 1.00 & 2 & 3 & 5 & 3.33 & 0.33 & 1 & 3 & 3 & 2.33 & 0.47 & 0.47 & 0.15 \\
\hline $\mathrm{R}_{22}$ & 1 & 3 & 4 & 2.67 & 0.37 & 2 & 4 & 4 & 3 & 33 & 2 & 2 & 5 & 3.00 & 0.60 & 0.22 & 0.20 \\
\hline $\mathrm{R}_{23}$ & 4 & 4 & 5 & 4.33 & 1.00 & 4 & 5 & 5 & 4.67 & 1.00 & 1 & 3 & 3 & 2.33 & 0.47 & 0.47 & 0.47 \\
\hline $\mathrm{R}_{24}$ & 1 & 1 & 3 & 1.67 & 0.00 & 1 & 4 & 4 & 3.00 & 0.17 & 1 & 4 & 4 & 3.00 & 0.60 & 0.00 & 0.10 \\
\hline $\mathrm{R}_{25}$ & 2 & 3 & 3 & 2.67 & 0.37 & 3 & 4 & 5 & 4.00 & 0.67 & 1 & 3 & 3 & 2.33 & 0.47 & 0.17 & 0.31 \\
\hline $\mathrm{R}_{26}$ & 3 & 4 & 5 & 4.00 & 0.88 & 3 & 4 & 5 & 4.00 & 0.67 & 2 & 4 & 4 & 3.33 & 0.67 & 0.58 & 0.44 \\
\hline $\mathrm{R}_{27}$ & 3 & 3 & 5 & 3.67 & 0.75 & 3 & 3 & 5 & 7 & 50 & 2 & 3 & 3 & 2.67 & 0.53 & 0.40 & 0.27 \\
\hline $\mathrm{R}_{28}$ & 4 & 4 & 5 & 4.33 & 1.00 & 4 & 5 & 5 & 4.67 & 1.00 & 1 & 2 & 3 & 2.00 & 0.40 & 0.40 & 0.40 \\
\hline $\mathrm{R}_{29}$ & 2 & 2 & 4 & 2.67 & 0.37 & 4 & 5 & 5 & 4.67 & 1.00 & 1 & 3 & 4 & 2.67 & 0.53 & 0.20 & 0.53 \\
\hline $\mathrm{R}_{30}$ & 2 & 4 & 5 & 3.67 & 0.75 & 3 & 4 & 5 & 4.00 & 0.67 & 1 & 1 & 3 & 1.67 & 0.33 & 0.25 & 0.22 \\
\hline $\mathrm{R}_{31}$ & 4 & 4 & 5 & 4.33 & 1.00 & 4 & 4 & 5 & 4.33 & 0.83 & 1 & 3 & 3 & 2.33 & 0.47 & 0.47 & 0.39 \\
\hline $\mathrm{R}_{32}$ & 2 & 2 & 5 & 3.00 & 0.50 & 2 & 3 & 5 & 3.33 & 0.33 & 1 & 2 & 2 & 1.67 & 0.33 & 0.17 & 0.11 \\
\hline $\mathrm{R}_{33}$ & 3 & 3 & 5 & 3.67 & 0.75 & 4 & 4 & 5 & 4.33 & 0.83 & 1 & 2 & 2 & 1.67 & 0.33 & 0.25 & 0.28 \\
\hline
\end{tabular}


Risk Critical Point (RCP)

this point has been illustrated with specific circular shape.

Steps 7: Finally, the four quarter zones were identified by means of risk critical point (RCP). These zones that are identified as critical, critical probability, critical impact, and non-critical, are shown in Figure (4).

\section{MONITORING THE RESULTS}

After identifying the four critical, critical probability, critical impact and non-critical zones, here the minimum impact of implementation of safety measurement will be identified by reducing either risks impact (X) or probability of occurrence (Y) comparing before

Table 8. Determination of RIP

\begin{tabular}{|c|c|c|c|c|c|c|c|c|c|}
\hline \multirow{2}{*}{$\begin{array}{l}\text { Risk } \\
\text { Codes }\end{array}$} & \multicolumn{2}{|c|}{ Risk probability } & \multicolumn{2}{|c|}{ Risk impact } & \multicolumn{2}{|c|}{ Safety performance } & \multicolumn{2}{|c|}{$\begin{array}{l}\text { Adjusted modified } \\
\text { scores }\end{array}$} & \multirow[t]{2}{*}{$\mathrm{MSP} \times \mathrm{MSI}$} \\
\hline & $\mathrm{y}_{\mathrm{i}}$ & $\mathrm{MP}_{\mathrm{i}}$ & $z_{i}$ & $\mathrm{MI}_{\mathrm{i}}$ & $\mathrm{x}_{\mathrm{i}}$ & $\operatorname{SPI}\left(R_{i}\right)$ & $\mathrm{M}\left(\mathrm{S}_{\mathrm{P}}\right)_{\mathrm{i}}$ & $\mathrm{M}\left(\mathrm{S}_{\mathrm{i}}\right)$ & \\
\hline $\mathrm{R}_{1}$ & 3.00 & 0.50 & 4.00 & 0.67 & 3.00 & 0.60 & 0.30 & 0.40 & 0.12 \\
\hline $\mathrm{R}_{2}$ & 2.67 & 0.37 & 4.33 & 0.83 & 3.00 & 0.60 & 0.22 & 0.50 & 0.11 \\
\hline $\mathrm{R}_{3}$ & 3.00 & 0.50 & 4.33 & 0.83 & 2.33 & 0.47 & 0.23 & 0.39 & 0.09 \\
\hline $\mathrm{R}_{4}$ & 2.67 & 0.37 & 3.33 & 0.33 & 3.67 & 0.73 & 0.27 & 0.24 & 0.07 \\
\hline $\mathrm{R}_{5}$ & 2.33 & 0.25 & 4.33 & 0.83 & 2.67 & 0.53 & 0.13 & 0.44 & 0.06 \\
\hline $\mathrm{R}_{6}$ & 3.67 & 0.75 & 3.67 & 0.50 & 1.67 & 0.33 & 0.25 & 0.17 & 0.04 \\
\hline $\mathrm{R}_{7}$ & 3.00 & 0.50 & 3.00 & 0.17 & 3.00 & 0.60 & 0.30 & 0.10 & 0.03 \\
\hline $\mathrm{R}_{8}$ & 2.67 & 0.37 & 4.33 & 0.83 & 3.67 & 0.73 & 0.27 & 0.61 & 0.17 \\
\hline $\mathrm{R}_{9}$ & 4.33 & 1.00 & 4.67 & 1.00 & 1.67 & 0.33 & 0.33 & 0.33 & 0.11 \\
\hline $\mathrm{R}_{10}$ & 2.67 & 0.37 & 3.00 & 0.17 & 2.67 & 0.53 & 0.20 & 0.09 & 0.02 \\
\hline $\mathrm{R}_{11}$ & 2.67 & 0.37 & 4.67 & 1.00 & 3.67 & 0.73 & 0.27 & 0.73 & 0.20 \\
\hline $\mathrm{R}_{12}$ & 4.00 & 0.88 & 4.00 & 0.67 & 2.33 & 0.47 & 0.41 & 0.31 & 0.13 \\
\hline $\mathrm{R}_{13}$ & 3.67 & 0.75 & 4.33 & 0.83 & 2.67 & 0.53 & 0.40 & 0.44 & 0.18 \\
\hline $\mathrm{R}_{14}$ & 2.67 & 0.37 & 4.33 & 0.83 & 2.00 & 0.40 & 0.15 & 0.33 & 0.05 \\
\hline $\mathrm{R}_{15}$ & 2.67 & 0.37 & 2.67 & 0.00 & 1.67 & 0.33 & 0.12 & 0.00 & 0.00 \\
\hline $\mathrm{R}_{16}$ & 3.67 & 0.75 & 4.33 & 0.83 & 1.33 & 0.27 & 0.20 & 0.22 & 0.04 \\
\hline $\mathrm{R}_{17}$ & 4.33 & 1.00 & 4.67 & 1.00 & 2.33 & 0.47 & 0.47 & 0.47 & 0.22 \\
\hline $\mathrm{R}_{18}$ & 4.00 & 0.88 & 4.67 & 1.00 & 2.67 & 0.53 & 0.47 & 0.53 & 0.25 \\
\hline $\mathrm{R}_{19}$ & 2.33 & 0.25 & 4.00 & 0.67 & 2.00 & 0.40 & 0.10 & 0.27 & 0.03 \\
\hline $\mathrm{R}_{20}$ & 3.67 & 0.75 & 4.67 & 1.00 & 2.67 & 0.53 & 0.40 & 0.53 & 0.21 \\
\hline $\mathrm{R}_{21}$ & 4.33 & 1.00 & 3.33 & 0.33 & 2.33 & 0.47 & 0.47 & 0.15 & 0.07 \\
\hline $\mathrm{R}_{22}$ & 2.67 & 0.37 & 3.33 & 0.33 & 3.00 & 0.60 & 0.22 & 0.20 & 0.04 \\
\hline $\mathrm{R}_{23}$ & 4.33 & 1.00 & 4.67 & 1.00 & 2.33 & 0.47 & 0.47 & 0.47 & 0.22 \\
\hline $\mathrm{R}_{24}$ & 1.67 & 0.00 & 3.00 & 0.17 & 3.00 & 0.60 & 0.00 & 0.10 & 0.00 \\
\hline $\mathrm{R}_{25}$ & 2.67 & 0.37 & 4.00 & 0.67 & 2.33 & 0.47 & 0.17 & 0.31 & 0.05 \\
\hline $\mathrm{R}_{26}$ & 4.00 & 0.88 & 4.00 & 0.67 & 3.33 & 0.67 & 0.58 & 0.44 & 0.26 \\
\hline $\mathrm{R}_{27}$ & 3.67 & 0.75 & 3.67 & 0.50 & 2.67 & 0.53 & 0.40 & 0.27 & 0.11 \\
\hline $\mathrm{R}_{28}$ & 4.33 & 1.00 & 4.67 & 1.00 & 2.00 & 0.40 & 0.40 & 0.40 & 0.16 \\
\hline $\mathrm{R}_{29}$ & 2.67 & 0.37 & 4.67 & 1.00 & 2.67 & 0.53 & 0.20 & 0.53 & 0.11 \\
\hline $\mathrm{R}_{30}$ & 3.67 & 0.75 & 4.00 & 0.67 & 1.67 & 0.33 & 0.25 & 0.22 & 0.06 \\
\hline $\mathrm{R}_{31}$ & 4.33 & 1.00 & 4.33 & 0.83 & 2.33 & 0.47 & 0.47 & 0.39 & 0.18 \\
\hline $\mathrm{R}_{32}$ & 3.00 & 0.50 & 3.33 & 0.33 & 1.67 & 0.33 & 0.17 & 0.11 & 0.02 \\
\hline $\mathrm{R}_{33}$ & 3.67 & 0.75 & 4.33 & 0.83 & 1.67 & 0.33 & 0.25 & 0.28 & 0.07 \\
\hline
\end{tabular}


considering the SPI, $\left(X_{I}, Y_{I}\right)$ and after doing so $\left(X_{2}, Y_{2}\right)$ (Figure 5). Later, it will be ascertained whether or not the obtained safety level of the project is acceptable. Increasing the safety level of a project depends on changing the existing condition of the project which requires changing the risk response to each risk. It means that the values of $M S_{I}$ and $M S_{P}$ of each risk can help decision makers to choose the most appropriate risk response in order to explicitly avoid, mitigate, transfer or accept the critical risks.

The core of risk response strategy selection is to allocate project resources for reasonable and effective risk reaction which ensures high project performance in terms of safety, which is the concern of this study. Therefore, during the process of making decisions about risk response strategies, risk managers must analyze the advantages and disadvantages of each strategy, and the potential severity and probability of loss incurred as a result of safety breaches. Managers should choose a suitable response strategy and also consider the combination and application of several strategies. In this method, the choice of a better safety risk response in order to reduce critical risks may need additional resources such as money or time, and this needs to be considered in the initial and planning stages of projects before reaching the execution stage. Additionally, it is also possible to modify the safety strategy in the controlling phase of risk management when a new risk emerges or a formerly identified safety risk is eliminated during the project execution stage. This is done by determining the new RIP and RCP of adjusted risks and modifying attitudes towards the new safety conditions of project.

\section{CONCLUSIONS}

In view of the difficulty of acquiring precise information for a quantitative assessment that does not lose sight of influences by risk indexes (i.e. probability, impact and safety performance), a quantitative safetybased method named RCP, was developed in this paper for particular applicability to construction projects. It allows measurement of the risk indexes and their relative weights and categorizes risk zones into critical, critical probability, critical impact and non-critical areas. The fuzzy set theory was incorporated into the RCP method to facilitate the replication of uncertainty and ambiguity in the human decision-making process. Some characteristics of the proposed method can be enumerated as:

(1) The proposed method is developed based on a risk analysis concept and fuzzy expert system. Risk analysis is applied as a concept to identify the level of risk of each risk factor, while the fuzzy expert system is used as the method to assess the level of risk in the risk assessment step. The fuzzy expert system was embedded in pre-designed questionnaires that were incorporated in the risk analysis technique to predict the risk level to determine the safety contingency value of the whole project.

(2) Since the scope of this study is limited to a numerical example from the high-rise construction industry, it is recognized that the safety aspect of risk is a third dimension of risk and does not include other project performance criteria such as cost, time, quality and environmental sustainability.

(3) One of the most significant advantages of the proposed methodology is that it will give investors a more rational basis for making decisions and it can prevent threats safety with optimal measures being taken for each risk.

(4) The method was designed using mathematical logic and principles such as Pareto optimality, resulting in a better understanding of critical and non-critical areas.

(5) As forecasted using the proposed model and reviewing the actual cost and performance of Milad project, it has been revealed that one of the major cost and schedule deviations during the project execution were corrective actions towards safety aspect of project risks. Therefore, using the proposed model in the very first stage of planning phase will cause the managers to have more accurate preventive actions instead of corrective ones for each corresponding risk that has been scaled correctly with considering its safety aspect in addition to its probability and impact.

Finally, believing there are still areas in the proposed method that need to be validated, the introduced case study does not necessarily provide an ideal measure of the relative performance and success of this method. Therefore, further research needs to be undertaken to bring this method to maturity and to compare the efficiency of the approach in any other construction fields in terms of various factors such as cost, time, quality and environmental sustainability to help with selection of the critical risks when a substantially reliable approach is needed. Such an extension would provide a better understanding of the RCP method.

\section{REFERENCES}

Aneziris, O. N., Papazoglou, I. A., and Kallianiotis, D. (2010), Occupational risk of tunneling construction, Safety Science, 48, 964-972.

Aneziris, O. N., Topali, E., and Papazoglou, I. A. (2011), Occupational risk of building construction, Reliability Engineering and System Safety, doi:10.1016/ j.ress.2011.11.003.

Baker, S., Ponniah, D., and Smith, S. (1999), Risk response techniques employed currently for major projects, Construction Management and Economics, London, 7(2), 205-213.

Caponecchia, C. and Sheils, I. (2011), Perceptions of per- 
sonal vulnerability to workplace hazards in the Australian construction industry, Journal of Safety Research, 42, 253-258.

Carbonari, A., Giretti, A., and Naticchia, B. (2011), A proactive system for real-time safety management in construction sites, Automation in Construction, 20, 686-698.

Chapman, R. J. (2001), The controlling influences on effective risk identification and assessment for construction design management, International Journal of Project Management, 19, 147-160.

Chenyun and Zichun, Y. (2012), The BP Artificial Neural Network Model on Expressway Construction Phase Risk, Systems Engineering Procedia, 4, 409415.

Deng, Y., Sadiq, R., Jiang, W., and Tesfamariam, S. (2011), Risk analysis in a linguistic environment: A fuzzy evidential reasoning-based approach, Expert Systems with Applications, 38, 15438-15446.

El-Sayegh, S. M. (2007), Risk assessment and allocation in the UAE construction industry, International Journal of Project Management, doi:10.1016/j. ijproman.2007.07.004.

Fouladgar, M. M., Yazdani-Chamzini, A., and Zavadska, E. K. (2012), Risk evaluation of tunneling projects, International Journal of Civil and Mechanical Engineering, 12, 1-12.

Fung, I. W. H., Lo, T. Y., and Tung, K. C. F. (2011), Tung Towards a better reliability of risk assessment: Development of a qualitative and quantitative risk evaluation model (Q2REM) for different trades of construction works in Hong Kong, International Journal of Accident Analysis and Prevention, AAP2470.

Fung, I. W. H., Tam, V. W. Y., Lo, T. Y., and Lu. L. L. H. (2010), Developing a Risk Assessment Model for construction safety, International Journal of Project Management, 28, 593-600.

Gangolells, M., Casals, M., Forcada, N., Roca, X., and Fuertes, A. (2010), Mitigating construction safety risks using prevention through design, Journal of Safety Research, 41, 107-122.

Guofeng, W., Min W., and Weiwei, Z. (2011), Study on the Existing Problems and Countermeasures of Project Risk Management in China, Energy Procedia, 13, 2726-2733.

Gurcanli, G. E. and Mungen, U. (2008), An occupational safety risk analysis method at construction sites using fuzzy sets, International Journal of Industrial Ergonomics, doi:10,1016/j.ergon.2008.10. 006.

Kaming, P. F., Olomolaiye, P. O., Holt, G. D., and Harris, F. C. (1997), Factors influencing construction time and cost overruns on high-rise projects in Indonesia, Construction Management and Economics, 15, 8394.

KarimiAzari, A., Mousavi, N., Mousavi, S. F., and Hosseini, S. B. (2011), Risk assessment model selection in construction industry, Expert Systems with
Applications, 38, 9105-9111.

Kucukali, S. (2011), Risk assessment of river-type hydropower plants using fuzzy logic approach, Energy Policy, 39, 6683-6688.

Lee, A. H. I. (2009), A fuzzy supplier selection model with the consideration of benefits, opportunities, costs and risks, Expert systems with Applications, 36, 2879-2893.

Lee, L. W. and Chen, S. M. (2008), Fuzzy risk analysis based on fuzzy numbers with different shapes and different deviations, Expert Systems with Applications, 34, 2763-2771.

Lin, W., Yaqi, L., and Enmao, W. (2011), Research on Risk Management of Railway Engineering Construction, Systems Engineering Procedia, 1, 174-180.

Mohammad, S., Mojtahedi , H., Mousavi, S. M., and Makui, A. (2010), Project risk identification and assessment simultaneously using multi-attribute group decision making technique, Safety Science, 48, 499507.

Nieto-Morote, A. and Ruz-Vila, F. (2011), A fuzzy approach to construction project risk assessment, International Journal of Project Management, 29, 220-231.

Pinto, A., Nunes, I. L., and Ribeiro, R. A. (2011), Occupational risk assessment in construction industryOverview and reflection, Safety Science, 49, 616624.

Roisenberg, M., Schoeninger, C., and da Silva, R. R. (2009), A hybrid fuzzy-probabilistic system for risk analysis in petroleum exploration prospects, Expert Systems with Applications, 36, 6282-6294.

Saifullah, N. M. and Ismail, F. (2012), Integration of Occupational Safety and Health during Preconstruction Stage in Malaysia, Procedia-Social and Behavioral Sciences, 35, 603-610.

Sousa, R. and Einstein, H. H. (2012), Risk analysis during tunnel construction using Bayesian Networks: Porto Metro case Study, Tunneling and Underground Space Technology, 27, 86-100.

Stroeve, H. S., Blom, H. A. P., and Bakker, G. J. (2009), Systemic accident risk assessment in air traffic by Monte Carlo simulation, Safety Science, 47, 238249.

Xiao-mei, G. and Xiao-jun, L. (2011), Application of Entropy Measurement in Risk Assessment of the Engineering Project of Construction-agent System, Systems Engineering Procedia, 1, 244-249.

Xu, Y., Yeung, J. F. Y., Chan, A. P. C., Chan, D. W. M., Wang, S. Q., and Ke, Y. (2010), Developing a risk assessment model for PPP projects in China-A fuzzy synthetic evaluation approach, Automation in Construction, 19, 929-943.

Zadeh, L. A. (1965), Fuzzy sets. Information and Control, 8, 338-353.

Zayed, T., Amer, M., and Pan, J. (2007), Assessing risk and uncertainty inherent in Chinese highway projects using AHP, International Journal of project management, doi:10.1016/j.ijproman.2007.05.12. 